Filol. linguist. port., n. 13(2), p. 269-303, 2011

\title{
Aspectos da categoria foco no português de Angola ${ }^{1}$
}

\section{Aspects of the focus category in Angolan Portuguese}

\author{
Eduardo Ferreira dos Santos ${ }^{2}$ \\ Márcia Santos Duarte de Oliveira ${ }^{3}$
}

\begin{abstract}
RESUMO: Nosso trabalho tem como objetivo apontar a categoria sintático-discursiva foco no português de Angola partindo de uma noção e tipologia específicas para essa categoria. A partir de uma interface morfossintaxe/discursiva, consideramos as sentenças clivadas e as pseudoclivadas como veiculadoras de foco por apresentarem uma leitura especificacional, em que há a obrigatoriedade de predicação de um valor a uma variável, disparando as leituras de 'contrastividade', 'exclusividade' e 'exaustividade', próprias do constituinte focalizado. Apresentamos, portanto, uma análise para o foco no português angolano, a partir da tipologia para as sentenças clivadas e pseudoclivadas realizadas com os estudos do português brasileiro. As sentenças tradicionalmente classificadas como 'interrogativas clivadas sem cópula' recebem, em nosso trabalho, uma proposta de análise em que consideramos esse tipo de sentença fora do âmbito das clivadas. Consideramos que o elemento fronteado que recebe a leitura de foco é seguido de uma partícula focalizadora apontando para um foco controlado gramaticalmente.
\end{abstract}

Palavras-chave: português de Angola, foco, clivagem

\begin{abstract}
Our work aims to point out the syntactic-discursive category focus in Angolan Portuguese, starting from a concept and typology specific to this category. Taking as a starting point a morphosyntax/discursive interface, we consider cleft and pseudo cleft sentences as being focus carrying, in that they present a specificational reading, containing an obligatory predication
\end{abstract}

1 Este trabalho resume as conclusões apresentadas sobre o foco no português de Angola apontadas na Dissertação de Mestrado de Eduardo F. dos Santos, sob orientação de Márcia Oliveira. Os autores agradecem os comentários e sugestões do parecerista e deixam claro que os problemas que persistirem são de suas responsabilidades.

2 Universidade de São Paulo, Doutorando Bolsista CNPq. E-mail: eduardo.santos@usp.br

3 Universidade de São Paulo: E-mail: marcia.oliveira@usp.br 
of value to a variable, expressing the readings of 'contrast', 'exclusiveness' and 'exhaustive', characteristic of the focussed constituent. We introduce an analysis of focus in Angolan Portuguese from the starting point of a typology for cleft and pseudo-cleft sentences as developed in studies of Brazilian Portuguese. For the sentences traditionally classified as interrogative cleft without copula', we propose an analysis in which we consider this kind of sentence outside of cleft classification. We consider that the fronted element receiving the focus reading is followed by a focusing particle pointing to a grammatically controlled focus.

Keywords: Angolan Portuguese, focus, cleft sentences

\section{Introdução}

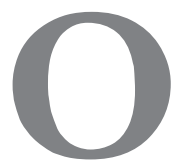

continente africano é um imenso espaço geográfico e abriga quase um terço das línguas do mundo.

[...] Uma recente autoridade (Grimes (ed.) 1996) coloca o número de linguas africanas na casa de 2.035: este número não é fixo, pois algumas línguas estão ainda sendo descobertas, enquanto outras, com poucos falantes, estão sendo eliminadas. [...] Heine \& Nurse (2000: 1, traduzido)

Considera-se o universo linguístico africano apenas a reunião das línguas nativas do continente, excluindo-se as línguas que foram introduzidas nos últimos dois mil anos, como: árabe, malagasiano, afrikaans, inglês, francês, espanhol e português ${ }^{4}$.

A situação atual no continente africano, que inclui Angola (o país que enfocamos nossa atenção) é caracterizada pelo multilinguismo em que estatutos e funções diferentes são associados às línguas:

(i) Lingua oficial: normalmente uma língua europeia, a do colonizador, na maioria dos países.

(ii) Lingua nacional: é uma das várias línguas locais escolhidas para serem descritas e normatizadas em razão de sua extensão e número de falantes, com o objetivo de serem ensinadas na escola e se tornarem língua oficial.

4 Exclui-se ainda da 'linguística africanista' as línguas crioulas (e pidgns) que são o resultado do fenômeno do 'contato linguístico' de: (i) língua(s) africana(s) com língua(s) do colonizador europeu - ex. caboverdiano e sãotomeense - e (ii) língua(s) africana(s) com outra(s) língua(s) africana(s) - ex. kituba e lingala - sobre 'pidgins e criolos', ver, entre outros, Holm (1989). 
(iii) Lingua veicular: é uma língua nacional que estabelece a comunicação entre falantes de línguas diferentes, muitas vezes de países vizinhos.

Em Angola, a língua oficial é a portuguesa, confirmando a adoção da língua do colonizador como oficial e usada nos órgãos oficiais do país e no ambiente escolar. As línguas nacionais são umbundu, kimbundu, kikongo e tchockwe, faladas por um grande número de falantes e distribuídas pelo território angolano. Essas línguas, na maioria dos casos, estão descritas e dispõem de gramáticas próprias como meio de serem normatizadas.

O multilinguismo em Angola é atestado em nosso corpus através da fala de um dos informantes ${ }^{5}$ :

E: E então, além do português, é capaz de entender ou falar outra língua de Angola, o kimbundu por exemplo?

Li36: Sim, é capaz sempre. É capaz sempre porque nós por exemplo, eu falar não sei mas percebo certas coisas que é kimbundu e a outra língua do Sul que é o umbundu. Entendo perfeitamente. (Chavagne, 2005:112)

O falante ao perceber "certas coisas que é kimbundu e a outra língua do Sul que é o umbundu" confirma a situação de se ter em Angola mais de uma língua nacional em situação de contato com a língua oficial - o português.

Seguindo Petter (2008: 39), a sociedade angolana é composta por uma variedade de grupos linguísticos, com predominância de línguas bantas e algumas línguas coissan. Atualmente, há um processo de gramatização das seis principais línguas e a sua posterior classificação como língua nacional, requisito básico para que cheguem ao status de língua oficial, posto ocupado pelo português. Outro aspecto levantado por Petter (2008), ratificando as considerações de Chavagne (2005), é o fato de se ter em Angola a língua portuguesa convivendo com outras línguas africanas.

A comprovação do multilinguismo reforça a questão que se coloca em Petter (2008): a importância de se entender questões relativas ao português falado em África a fim de se entender o português falado no Brasil - PB. Isso 
parte da assunção de que algumas características do PB têm origem em línguas do oeste da África - ver entre outros, Fiorin \& Petter (2008).

Atualmente, em Angola, diversas discussões entre intelectuais e profissionais da área de ensino e linguagem mais o governo estão em pauta sobre os caminhos a serem seguidos na questão do ensino e aprendizagem da língua portuguesa em um contexto claramente multilíngue que se atesta nesse país.

Zau (2009), ao analisar projetos colocados à apreciação pública sobre a política linguística a ser adotada em Angola, chama a atenção para o fato de que, nesses projetos, se abandona a designação 'línguas nacionais' e todas as outras línguas de origem africana passam a ser designadas como 'demais línguas de Angola’. Afirma também que a língua portuguesa não é suficientemente dominada pela maioria dos angolanos, mas que é a única falada de 'Cabinda ao Cunene', representando uma cobertura nacional em termos de território dentro de um ambiente multilíngue. $\mathrm{O}$ autor levanta a seguinte discussão:

[...] as principais línguas de comunicação internacional (inglês e francês) são estrangeiras, mas têm um estatuto, porque fazem parte de currículos do nosso sistema educativo. Porém, se consideramos a necessidade de valorização, promoção do estudo, ensino e utilização das 'demais línguas de Angola’, falta saber que estatuto político terá de ser dado a cada uma das línguas de origem africana faladas em Angola (nacionais, regionais, locais...).( Zau, 2009 - página da internet)

A questão levantada por Zau (2009) mais uma vez ratifica a situação de multilinguismo no território angolano e aponta para a necessidade da adoção de uma política linguística que leve em conta a realidade social e linguistica de seus falantes. Desse modo, apontam-se, também, novos caminhos para os estudos linguísticos da língua portuguesa falada em Angola e da situação das línguas classificadas como 'línguas nacionais'.

A seguir passamos ao desenvolvimento do trabalho. Na seção dois introduzimos informações a respeito do corpus e dos dados que serviram de base para esse estudo; na seção três resumimos o conceito, a tipologia e a realização da categoria foco. As seções quatro e cinco são dedicadas à apresentação da tipologia da clivagem e pseudoclivagem e seguindo a elas, na seção seis, passamos à abordagem da análise da clivagem do PA. Nas seções sete e oito seguem-se a conclusão e as referências bibliográficas do trabalho. 


\section{Sobre o corpus e os dados}

Para a abordagem da categoria foco no português angolano - daqui em diante PA - obtivemos os dados a partir de um corpus presente em Chavagne (2005). O autor, ao final de sua tese de doutorado, apresenta um anexo - Annexe 1: Corpus Oral Transcrit - constituído de oito transcrições que serviram de base para seu estudo sobre as principais características do português angolano em comparação com o português europeu - PE - e aproximações com o português brasileiro.

As transcrições contidas no anexo de Chavagne (2005) são compostas de diferentes situações de falas com diferentes interlocutores em contextos de ambiente universitário, programas de rádio, de televisão, registros de interpretação de atores em textos paródicos sobre a língua popular angolana e entrevistas com intelectuais de Angola. A partir dessa diversidade de interlocutores, nota-se que o corpus privilegia uma variedade do português angolano que podemos considerar como 'português angolano culto', falado por universitários, repórteres, escritores e pessoas com grau de instrução escolar relativamente qualificado.

A proposta de transcrição de Chavagne mostrou-se útil para nosso trabalho, pois apontava o contexto em que o conteúdo era expresso, permitindo uma reorganização desse conteúdo em dados específicos que apresentassem sentenças clivadas e pseudoclivadas ${ }^{6}$.

\section{A categoria foco}

Nesta seção, assumimos a abordagem de foco de Zubizarreta (1997:1, traduzido) que diz que: "[...] foco é definido em termos da noção discursiva de pressuposição: o foco é a parte não pressuposta da sentença." . Ao estudarmos sobre a categoria foco, estamos diante de um fenômeno de interface sintático/discursivo.

Zubizarreta (1997) propõe que a interpretação de um constituinte focalizado deve ser representada por meio de duas asserções (A) no nível da

6 Por se tratar de um corpus transcrito, não pudemos considerar aspectos prosódicos para a apreensão do foco em nosso trabalho. Por esse motivo, privilegiamos construções 'marcadas' como as clivadas e pseudoclivadas que são construções tipicamente veiculadoras de foco. Nas seções 3 e 4, abordamos com mais detalhes essa questão.

7 A pressuposição é entendida como o 'cenário' da sentença que se supõe partilhada pelos falantes. 
Forma Lógica (LF): $\mathrm{A}_{1}, \mathrm{~A}_{2}$, chamadas de estrutura de asserção (AS) pela autora, conforme notamos abaixo para um elemento focalizado [F o chá] em:

(01) Foi o chá que o Pedro bebeu

$\mathbf{A}_{1}$ : Existe um $x$ tal que o Pedro bebeu $x$.

$\mathbf{A}_{2}$ : O x tal que o Pedro bebeu $x=\left[{ }_{F}\right.$ o chá $]$.

Em (01), a $A_{1}$ representa o contexto assertivo ou a pressuposição da sentença; a $A_{2}$ recebe a denominação de asserção principal, sendo uma sentença equativa que possui como predicado o elemento focalizado.

Além da definição de foco que seguimos nesse trabalho, e apontada acima, é preciso ainda afirmar que essa categoria possui uma 'tipologia específica', resenhada em Oliveira (no prelo) e que apresentamos abaixo.

Além da definição de foco que seguimos nesse trabalho, e apontada acima, é preciso ainda afirmar que essa categoria possui uma tipologia específica, resenhada em Oliveira (no prelo) e que apresentamos abaixo.

Oliveira aponta a proposta de Kuno $(1972$, !975) e Chafe (1976) para a existência de uma diversidade funcional para o sistema de foco. Para Kuno (1972), as distinções como "tema", "contraste", "lista exaustiva" e "descrição neutra" apresentam um papel decisivo na sintaxe da língua japonesa (com equivalentes no inglês também); Chafe (1976) expande a tipologia de Kuno $(1972,1975)$ propondo o "foco de listagem exaustiva". É a partir de Chafe que temos o uso da terminologia de "foco contrastivo".

Os trabalhos de Zubizarreta (1998) e Kiss (1998) definem a principal tipologia usada na literatura sobre foco:

(I) foco informacional (foco assertivo);

(II) foco contrastivo;

(III) foco de listagem exaustiva.

A língua portuguesa, por exemplo, mostra tipologicamente, através de sua sintaxe (ordem e tipo de sentença - como as clivadas e pseudoclivadas) e de sua fonologia (entonação), o foco assertivo ou contrastivo. No entanto, 
Oliveira chama a atenção para o fato de que a literatura africanista aponta para uma tipologia de foco mais abrangente do que a citada acima. É o caso de Watters (1979) que apresenta um estudo detalhado do foco em aghem (uma língua bantoide falada em Camarões).

Além da tipologia de foco, chamamos a atenção para a 'realização do foco'. Unindo diretamente uma função discursiva com uma marcação gramatical, o foco pode ser realizado nos níveis sintático, morfológico e fonológico (prosódico).

Na sintaxe, destacamos, por exemplo, os estudos sobre o foco na posição de sujeito no PE e PB. Kato \& Raposo (1996), entre outros, apontam que, no $\mathrm{PE}$, o sujeito focalizado ocorre posposto ao verbo - ordem VS - diferentemente do que se atesta no PB. Vejamos, em (02), uma sentença do tipo pergunta-QU (contexto de apreensão de foco), seguida, em (03), das sentenças-respostas (foco) em PE/PB:

(02) Quem comprou o carro?

(03) a. (O carro) comprou a Maria. (PE/*PB)

b. (O carro) A Maria comprou. (*PE/PB)

Em (03), o DP (sintagma determinante) “a Maria”, que responde à pergunta-QU em (02) e funciona como foco, ocorre em diferentes posições nas duas línguas - PE/PB; o DP apresenta uma entonação especial que é parte da marcação gramatical do foco em português.

No nível morfológico, algumas línguas fazem a marcação do foco através de uma partícula, como ocorre em ioruba:

\section{Maria ni o fun omo ni osan lanaa ${ }^{8}$}

$\begin{array}{lllllll}\text { Maria ni } & \text { ni } & \text { fun } & \text { omo } & \text { ni } & \text { osan lanaa } \\ \text { Maria FOC } & ? & \text { gave } & \text { baby } & \text { an } & \text { orange } & \text { yesterday } \\ \text { 'It was } & \text { Mary who gave the baby an orange yesterday' }\end{array}$

8 Adesanya (2007: 151). The example was renumbered; bold face characters are our own; the glossing line is ours. 
No exemplo acima, a partícula focalizadora ni ocorre imediatamente após o sintagma que recebe a leitura de foco.

Com relação à interface sintaxe/fonologia, na língua portuguesa (e em muitas outras línguas indoeuropeias), a proeminência prosódica tem papel fundamental na marcação do foco. Análises gráficas do contorno entonacional entre sentenças neutras e sentenças com marcação de foco em um dado sintagma, por exemplo, apontam para um contorno entonacional especial no elemento focalizado, pois a interface sintaxe/fonologia "lê" uma pressuposição pragmática $(f \circ c))^{9}$.

Neste trabalho, conforme já mencionamos na seção 2, nosso corpus constitui-se de transcrições da oralidade culta do português angolano (PA) - Chavagne (2005). Por não dispormos de gravações desses dados, que nos impossibilitou de realizar uma análise, ainda que preliminar, da prosódia do foco nessa língua, centramo-nos na apreensão do foco, em PA, voltada para a interface morfossintaxe/discursiva, priorizando o tratamento de dados com sentenças clivadas e pseudoclivadas.

\section{Clivadas}

Uma maneira de se estudar o foco em uma abordagem morfossintática está na consideração de estruturas conhecidas na literatura como clivagem. Tomada como uma sentença 'marcada', assim como as pseudoclivadas e perguntas-QU fronteadas, a clivada é o resultado de uma operação de 'ensanduichamento' de um dado sintagma da sentença entre uma cópula e um 'que', como vemos no sintagma uma casa, abaixo:

(05) Foi uma casa $a_{i}$ que ele comprou_t $\mathrm{t}_{\mathrm{i}}$ (e não um carro).

A operação 'clivagem' é realizada para destacar sintaticamente o foco da pressuposição. Nesse trabalho, assumimos a abordagem de leitura semântica da clivagem que se vê em Modesto (2001), ratificada em Mioto \& Negrão (2007) - daqui em diante, $M \& N$.

9 Remetemos o leitor a Fernandes (2007) para um estudo específico da interface sintaxe/ fonologia nos estudos do foco no português brasileiro e europeu. 
Para M\&N, nem toda construção em que um dado elemento ocorre 'ensanduichado' entre cópula e palavra 'que’ é uma clivagem. Esses autores, seguindo Modesto (2001: 37), tomam as leituras de 'contraste', 'exclusividade' e 'exaustividade' como as principais características das construções clivadas, ao lado da 'leitura especificacional' ${ }^{10}$.

Nas sentenças especificacionais há a 'especificação' de um valor a uma variável. Para as clivadas, o constituinte focalizado funciona como esse valor e a sentença introduzida pelo que é a variável, conforme o exemplo abaixo:

(06) [É a maçã que] ela está descascando valor: a maçã variável: x que ela está descascando

O processo de clivagem gera uma predicação com leitura especificacional caracterizada pela obrigatoriedade de atribuição de um valor a uma variável - ver Modesto (2001: 33) ${ }^{11}$. Assim, para a sentença em (06), atribuímos à variável um valor que deve ser, obrigatoriamente, o foco da sentença - a maçã - pois ao final da sentença poderíamos proferir:

(07) É a maça que ela está descascando (não a banana)

10 Chamamos a atenção do leitor para o fato de que 'leitura de exaustividade' não deve ser confundida com a tipologia de 'foco de listagem exaustiva' - ver seção (3). Logo, em português, por exemplo, nas sentenças clivadas, teremos sempre a leitura de exaustividade, mas não teremos nunca um foco do tipo de listagem exaustiva (como ocorre em japonês). Sentenças clivadas em português podem ser apenas do tipo assertivo (de informação) ou contrastivo.

11 As sentenças especificacionais são o contrário das sentenças predicacionais. As sentenças predicacionais predicam uma propriedade sem a especificação de um valor, e "não mostram contraste, nem exaustividade (já que nenhum valor é atribuído à variável" (Modesto, 2001: 40). Vejamos a sentença em (i) - Modesto (op.cit) - com valor predicacional:

(i) O que ele faz é lucrativo.

Para Modesto, em (i), depreeende-se uma leitura predicacional (não especificacional). $\mathrm{Na}$ leitura predicacional em (i), há a pressuposição de que alguma coisa é feita por ele, mas essa 'alguma coisa feita por ele' não implica não ser alguma outra coisa (i.e., há ausência de 'contrastividade', 'exaustividade'). Em (i), por exemplo, pode-se acrescentar à propriedade 'lucrativo', a propriedade 'benéfico' como se vê em:

(i') O que ele faz é lucrativo e TAMBÉM benéfico. 
A relação entre valor/variável presente nas sentenças clivadas é a responsável pelas leituras de contraste, já que a atribuição de um valor a uma variável faz um contraste com todos os outros valores que não foram selecionados e ainda acrescenta leitura de exclusividade, conforme o exemplo abaixo:

(08) É o Pedro que gosta da Maria (não o Carlos/*e o Carlos também) $)^{12}$

Em (08), pressupõe-se que assim como alguém gosta da Maria (pressuposição de existência), há pelo menos uma pessoa que não gosta (pressuposição de exclusividade). A leitura de exaustividade está em todos os valores que satisfazem a variável das clivadas.

A abordagem que seguem M\&N sobre clivadas com foco apresentarem, obrigatoriamente, uma leitura especificacional - e não predicacional - no sentido de Modesto (2001), tem uma implicação importante dentro da análise tradicional que se toma para as clivadas. Ao assumirmos que as clivadas apresentam uma leitura especificacional, excluímos a análise de que essas mesmas sentenças contenham uma relativa ${ }^{13}$.

\subsection{Tipologia das Clivadas no Português}

Seguindo a apresentação de Braga, Kato \& Mioto (2009: 255) para o português culto falado no Brasil - PB - e Ribeiro \& Côrtes Junior (2009: 209) para o português afro-brasileiro, apresentamos, nesta subseção, os tipos de sentenças clivadas apontadas para o português brasileiro, que tomamos como direcionamento para a análise das clivadas em PA.

As diferenças entre PE e PB, no tocante às construções clivadas, ocorre na predileção do tipo de sentenças clivadas:

[...] Quanto ao uso das estruturas clivadas realizadas nas duas variedades de português, os tipos de clivadas escolhidos são diferentes nas duas variedades. Enquanto no tipo de estrutura clivada produzida em PE, o sujeito se encontra na margem direita da sentença (pseudo-

12 Dado (24), extraído de Modesto (2001: 36), renumerado.

13 Para uma maior discussão sobre o CP - sintagma complementizador - das sentenças clivadas ser ou não relativo, remetemos o leitor a Modesto (2001); Mioto \& Negrão (2007); Braga, Kato \& Mioto (2009) e Santos (2010). 
-clivadas:'Quem chegou foram as velhas'), nos tipos de clivadas produzidas em PB, o sujeito se encontra na margem esquerda (clivadas invertidas com cópula: 'As velhas é que chegaram'; clivadas invertidas sem cópula 'As velhas que chegaram'; clivadas: 'Foram as velhas que chegaram').[...] (Fernandes, 2007: 179)

Pela razão explicitada em Fernandes (2007), a descrição da tipologia de clivadas, a seguir, é apreendida dos trabalhos de clivagem sobre o português brasileiro.

\subsubsection{Clivadas Canônicas Pessoais e Impessoais}

Segundo a literatura, considera-se clivada canônica aquela em que depois da cópula, temos o foco que é seguido por uma sentença encabeçada por um que $e^{14}$ O foco, nas clivadas canônicas, pode ser do tipo informacional ou contrastivo, como vemos $\mathrm{em}^{15}$ :

(09) a. Foram [as crianças] que viram a Gabriela

b. É [o João] que saiu (versus Foi o João que saiu)

c. É [os meninos] que vão comigo

Em (09a), observa-se que a cópula - foram - concorda com o elemento clivado em pessoa e número - as crianças - já que esse elemento clivado é de natureza nominal, assim como concorda, também, com o tempo do verbo subordinado - viram (passado). Segundo Braga, Kato \& Mioto (2009: 256), no português brasileiro popular, prefere-se a clivada sem concordância de tempo (09b) ou de número e pessoa (09c), chamadas de clivadas 'impessoais'.

\subsubsection{Clivadas Invertidas}

Braga, Kato \& Mioto (2007: 257) definem a clivada invertida como a sentença em que o foco é invertido para antes da cópula, que tende a permanecer invariante. $\mathrm{O}$ foco, neste tipo de clivada, tem sempre uma leitura contrastiva ${ }^{16}$

\footnotetext{
14 Ribeiro \& Côrtes Junior (2009:218) classificam as clivadas canônicas como 'clivadas básicas'.

15 Braga, Kato \& Mioto (2009:256), dado (26a, b, c) renumerado.

16 Braga, Kato \& Mioto (2009:257), dado (28a, b) renumerado.
} 
(10) a. [As crianças] é que viram a Gabriela, (não os vizinhos)

b. [A Gabriela] é que as crianças viram, (não a Margarida)

\subsubsection{Clivadas Sem Cópula ou Reduzidas}

Braga, Kato \& Mioto (2007:258) e Ribeiro \& Côrtes Junior (2009:220) definem as clivadas sem cópula ou reduzidas como sentenças clivadas que podem aparecer sem a realização da cópula, como vemos $\mathrm{em}^{17}$ :

(11) a. [Eu] que entro (versus (É) eu que entro)

b. Um só nada faz, [o conjunto] que opera (versus Um só nada faz, (é) o conjunto que opera

\subsubsection{Clivadas Apresentativas}

Para Braga, Kato \& Mioto (2007: 261), esse tipo de clivada não configura um foco de constituinte em específico, mas sim em uma sentença em que todos os constituintes são focalizados ${ }^{18}$ :

(12) A: - Você podia ir ao centro da cidade pagar estas contas para mim.

B: - (Acho que não. Acho que ninguém devia andar pelo centro. Está muito perigoso). É que [bandidos estão matando policiais].

Chamamos a atenção do leitor para o fato de que esse tipo de clivada foi primeiramente descrito para o português (europeu) por João Malaca Casteleiro (1976/1979) ao abordar a sintaxe e a semântica das construções enfáticas com 'é que'.

\subsubsection{Interrogativas Clivadas}

No tipo de clivada interrogativa, Braga, Kato \& Mioto (2009: 270) atestam uma estrutura com a cópula e o complementizador que seguindo um sintagma-QU como se vêem $\mathrm{em}^{19}$ :

17 Braga, Kato \& Mioto (2009: 257), dado (30a, b) renumerado.

18 Braga, Kato \& Mioto (2009:261), dado (39) renumerado.

19 Braga, Kato \& Mioto (2009:270), dado (60a, b, c) renumerado. 
(12) a. que é que um professor faz...?

b. o que é que a gente fazia como é que era....a:: a verificação no nosso tempo de escola?

c. o que foi que vocês encontraram?

Chamamos a atenção do leitor para o fato de que poderíamos integrar esse tipo de clivada à 'clivada invertida' (4.1.2.). No entanto, essa integração não nos interessa, pois em (4.1.2.) se focaliza um elemento não-QU e nessa subseção temos a focalização de um elemento-QU. Logo, o tipo de focalização é distinto.

\subsubsection{Clivadas com Dupla Cópula}

Ribeiro \& Côrtes Junior (2009: 221) apontam sentenças em que dizem ocorrer uma dupla realização da cópula, ou duplo marcador de foco. Os autores indicam a gramaticalização de é que como um único constituinte gramatical ${ }^{20}$ :

a. é por isso é que eu tem...

b. aí é aonde é que eu to lhe dizeno

\subsubsection{Interrogativas Clivadas sem Cópula}

Em Braga, Kato \& Mioto (2009: 270), vêem-se as seguintes orações ${ }^{21}$ :

(14) a. quem que a senhora acha que cuida de toda essa parte?

b. qual que seria o material?

c. por que que a senhora gostou dessa peça?

d. você sabe o que que é UPC?

As orações em (14) são analisadas pelos autores (op. cit.), entre outros, como interrogativas clivadas sem cópula que apresentam uma expressão-QU interrogativa na periferia esquerda da sentença, seguida pelo complementizador que. Essas construções têm sido referidas ainda como construções com "complementizador duplamente preenchido".

Kato \& Raposo (1996), entre outros, analisam sentenças como as em (14) como resultado de um apagamento da cópula - exemplo: (14a) quem (é)

\footnotetext{
20 Ribeiro \& Côrtes Junior (2009: 221), dado (37 a,b) renumerado.

21 Braga, Kato \& Mioto (2009:270), dado (61a, b, c, d) renumerado.
} 
que a senhora ach a que cuida de toda essa parte?. Os autores chamam a atenção para o fato dessa estrutura não ser atestada no português europeu, sendo, portanto, segundo eles, um ineditismo do português brasileiro.

Tal como em (4.1.5.), poderíamos integrar esse tipo de clivada à 'clivada sem cópula ou reduzidas’ (4.1.3.). No entanto, essa integração não nos interessa, pois em (4.1.3.) se focaliza um elemento não-QU e nessa subseção temos a focalização de um elemento-QU. Logo, o tipo de focalização, a nosso ver, é distinto.

Em nosso trabalho, consideramos as sentenças 'interrogativas clivadas sem cópula' fora do âmbito da classificação para as clivadas que explanamos acima. Conforme apontamos a seguir, tratamos as 'interrogativas clivadas sem cópula' como sentenças monoclausais com marcação morfológica explícita de foco, seguindo a proposta de Oliveira (no prelo).

\subsubsection{Perguntas QU Fronteadas Seguidas de ‘Que’ sem Cópula}

Como já dito, consideraremos, em nossa análise das clivadas do PA, no tocante às perguntas QU fronteadas, seguidas de que sem cópula, como construções monoclausais e não como construções clivadas (biclausais). A seguir, resumimos brevemente Oliveira (no prelo) que ratifica essa proposta para a análise dessas construções no $\mathrm{PB} /$ português afro-brasileiro.

Oliveira (no prelo) - daqui em diante, Oliveira -, no tocante ao fenômeno em destaque: perguntas-QU fronteadas, seguidas de 'que' e sem presença de cópula chama a atenção para o fato de que tipos sentenciais como(14) são amplamente atestados em todo o Brasil, seja por falantes cultos e não cultos. A argumentação da autora centra-se em apresentar trabalhos que analisam tais construções como 'clivadas com ausência de cópula'.

Oliveira apresenta, com fins argumentativos, outro exemplo dessa construção ${ }^{22}$ :

(15) *PE/PB/PVB O que que você fez?

22 Oliveira (no prelo: dado (1), renumerado). 
A autora aponta que, em (15), observa-se que o sintagma QU o que sofre aparente movimento da posição de argumento interno do verbo faz̧er para a periferia esquerda da sentença. Enfatiza que, em línguas como o português, elementos QU podem permanecer in situ ou serem movidos; quando movidos, os elementos QU, de acordo com a literatura, estão ligados a estruturas de clivagem.

Oliveira remete-nos a Cheng (1991), um texto clássico que afirma que em línguas do tipo QU-in situ e QU movido, como o PB, a opção de movimento QU nunca estaria disponível. Para Cheng, nas construções em que um dado sintagma interrogativo se encontra na periferia esquerda (como o que em (15)), tal sintagma teria sido gerado diretamente nessa posição. Logo, elementos-QUs na periferia da sentença como em (15) seriam elementos interrogativos derivados de 'orações clivadas reduzidas'. Abaixo, Cheng (apud Oliveira) exemplifica esse tipo de análise ${ }^{23}$ :

(16) a. Estrutura da clivada completa

It is $\left\{_{\mathrm{CP}}\left\{\left\{_{\mathrm{DP}}\right.\right.\right.$ Sharon $\}\left\{_{\mathrm{CP}} \mathrm{OP}\right.$ that $\left\{_{\mathrm{IP}}\right.$ Marcia likes $\left.\left.\left.\mathrm{t}_{\mathrm{i}}\right\}\right\}\right\}$

b. Estrutura da clivada reduzida

$\left\{_{C P}\left\{\min _{\mathrm{D}}\right\}\left\{_{\mathrm{CP}} \mathrm{OP}_{\mathrm{i}}\right.\right.$ illi $\left\{_{\mathrm{IP}}\right.$ Mona shaafit-uh $\left.\left.\left.{ }_{\mathrm{i}}\right\}\right\}\right\}$

Quem que Mona viu-ele

"Who did Mona see?"

Oliveira chama a atenção para o fato de, em (16), Cheng associar a sentença (16b) - árabe egípcio - a uma sentença clivada em inglês - (16a). Logo, (16b) é analisada por Cheng como clivada reduzida. Cheng (1991) estende essa mesma análise dada ao árabe egípcio (16b) para o bahasa indonesiano e também para o palauan, uma vez que essas línguas também apresentam as similaridades entre clivadas e perguntas-QU existentes em árabe, segundo a autora.

Textos clássicos em português sobre o fenômeno atestado em estruturas como em (15) seguem a análise de Cheng (1991). Esse é o caso que se vê em Kato \& Raposo (1994). Observe os dados abaixo em PE, PB e afro-brasileiro ${ }^{24}$ :

\footnotetext{
23 Oliveira (no prelo: dado (16)); apud Cheng (1991: 64).

24 Oliveira (no prelo: dado (17), renumerado).
} 
(17) a. PE; PB/PVB Você fez o quê?

b. PE; PB/PVB O que é que você fez?

c. *PE; PB/PVB O que que você fez?

Oliveira, explicando os dados acima, afirma que em PE, PB e português afro-brasileiro, perguntas-QU podem ser movidas para a periferia da sentença. Porém, em PE, esse movimento só ocorre de dentro de uma estrutura de clivagem como se atesta em (17). Sentenças como (17c) são agramaticais em PE. A autora nos informa que, segundo Kato \& Raposo (1996: 273-274), todas as perguntas-QU fronteadas em PB, como (17b,c), são interrogativas derivadas de clivagem, como se exemplifica abaixo por meio dos dados (17), renumerados ${ }^{25}$ :

(18) a. WH in-situ

PE/ PB/PVB Você fez oque?

b. WH movido para estrutura de clivagem

$\mathrm{PE} / \mathrm{PB} / \mathrm{PVB} \underline{\mathrm{O} \text { que é que você fez? }}$

c. Regra de apagamento de cópula em construções clivadas ${ }^{26}$

*PE/ PB/PVB O que que você fez?

d. Regra de apagamento do complementizador que

$\mathrm{PE} / \mathrm{PB} / \mathrm{PVB} \underline{\mathrm{O} q u e}$ você fez?

Com relação à análise apresentada em (18), Oliveira nos remete a Grolla (2005) que evidencia problemas em se atrelar a explicação de sentenças com elementos-QU na periferia esquerda da sentença em PB - como se vêem em (18c,d) - a estruturas de clivagem como o fazem Kato \& Raposo (1996), seguindo a proposta de Cheng (1991). Entre os problemas teóricos apresentados por Grolla, Oliveira enfatiza a 'aquisição de perguntas-QU em PB': segundo Grolla, as pesquisas apontam que, durante o processo de aquisição do $\mathrm{PB}$, as crianças começam a produzir orações com QUs deslocados - como (18d) - o que você fez?? -, muito

25 Oliveira (no prelo: dado (18), renumerado).

26 Chamamos a atenção do leitor para o fato de que foge do escopo de nosso trabalho apontar detalhes sobre a hipótese de Kato \& Raposo (1996). Por exemplo, em (18c), na 'Regra de apagamento de cópula em construções clivadas', os autores assumem, numa primeira fase da derivação, que havia uma cópula e que, posteriormente, ela foi apagada. Se isso é verdade, uma pergunta pode ser feita: "o que motiva o apagamento da cópula?". 
antes de produzir a primeira sentença clivada como (18b) - o que é que você fea?. Para Grolla, seria então necessário assumir que a criança adquire uma estrutura derivada antes mesmo de adquirir a estrutura que a origina.

Oliveira remete-nos ainda a Kato \& Mioto (2005). Esses autores ratificam a proposta de clivagem sem cópula para sintagmas-QU na periferia esquerda da sentença em PB, propondo que, em sentenças como (18c) - o que que vocêfez - a forma sem a cópula, se origina da gramaticalização de clivadas canônicas como $\mathrm{em}^{27}$ :

(19) É [FPquem ] que a Maria viu?

Oliveira aponta que, para Kato \& Mioto (2005), o apagamento da cópula não pode ocorrer em outros contextos, mas somente em início de sentença como se vê em (19) e corroboram sua proposta com sentenças monoargumentais como $\mathrm{em}^{28}$ :

(20) a. * O seu cabelo _ bonito.

b. __ Bonito o seu cabelo.

Para Oliveira, se sentenças-QU como (18c) são um tipo de clivagem reduzida, como se afirma na literatura, tais sentenças deveriam apresentar comportamento de clivadas. No entanto, não apresentam nenhuma das características do foco, como a determinação de uma 'tipologia fechada' e ainda de uma entonação especial - ver seção (3). Logo, Oliveira apresenta duas perguntas:

(i) qual a tipologia de foco que se vê em (24c)?

(ii) há pico entonacional de foco presente no elemento focalizado em (24c), no caso na pergunta-QU?

As respostas às duas perguntas acima, para Oliveira, têm que ser negativas. Não há uma tipologia de foco envolvendo a pergunta-QU em (18c) em PB/português afro-brasileiro - nem 'contrastivo', nem 'assertivo'; e nem há pico entonacional especial em o que. Logo, Oliveira argumenta que tais construções não são re-

\footnotetext{
27 Oliveira (no prelo: dado (19), renumerado). Omite-se, no dado, a tradução para o inglês.

28 Oliveira (no prelo: dado (20), renumerado).
} 
sultativas de construções clivadas com uma regra de apagamento de cópula como se vêem, entre outros em Kato \& Raposo (1996) e Kato \& Mioto (2005).

Para Oliveira, sentenças como (18c) - o que que vocêfę? - em PB/português afro-brasileiro podem estar atreladas ao fenômeno de contato com línguas do oeste africano - daqui em diante, LAs - que exibem o mesmo fenômeno gramatical. Portanto, a autora procede a uma comparação desse tipo de construção em PB/português afro-brasileiro com: (i) de uma lado, LAs e (ii) de outro lado com um conjunto de línguas crioulas do Atlântico - diretamente ligadas, como o PB/português afro-brasileiro, ao fenômeno de contato com LAs.

Oliveira em seu trabalho aponta um longo debate entre linguistas africanistas, crioulistas e de outras partes do globo envolvidos na análise desse tipo de fenômeno tratado aqui: perguntas-QU fronteadas, seguidas de 'que' e sem presença de cópula. A questão é: trata-se de uma estrutura biclausal (clivagem) ou monoclausal? No tocante ao PB e ao português afro-brasileiro, o fato de se colocar a análise dessas construções ao lado das hipóteses 'monoclausais', ou seja, daquelas hipóteses defendidas por linguistas africanistas como Green (2007) (para análises de línguas como o hausa), de que não se tratam de construções com 'apagamento de cópula', mas sim de construções específicas de marcação de foco, aproxima o PB/ português afro-brasieiro de traços linguísticos areais de LAs. Logo, esse fenômeno gramatical pode estar atrelado, segundo Oliveira, ao extremo fenômeno do contato linguístico/cultural que se deu durante o período das Grandes Navegações, envolvendo povos da África e do Novo Mundo.

Para detalhes de toda a argumentação de Oliveira no tocante às línguas africanas, crioulas e mesmo outras línguas de outras partes do mundo manifestando o fenômeno perguntas-QU fronteadas, seguidas de 'que' e sem presença de cópula serem analisadas como estruturas monoclausais (e não serem clivadas sem cópula) ver: Oliveira \& Holm (2011), Oliveira (no prelo).

\section{Pseudoclivadas}

A clivagem é um processo usado para a focalização de constituintes e envolve dois subconjuntos: (i) clivadas e (ii) pseudoclivadas.

A ordem básica das pseudoclivadas canônicas aponta para uma sequência em que temos: 
(21) sentença $\mathrm{WH}+$ cópula + XP

Observe as orações abaixo:

(22) a. Quem quer cozinhar?

b. Quem quer cozinhar é [a Joana].

Na pseudoclivada em15mas somente as que apresentarem leitura especificacional ${ }^{29}$. A leitura especificacional é a única que permite a 'especificação' de um valor a uma variável (foco) e ainda apresenta as leituras de contraste, exclusividade e exaustividade como as principais características das construções clivadas - ver Modesto (2001: 37).

\subsection{Tipologia das Pseudoclivadas no Português}

Seguindo a apresentação de Braga, Kato \& Mioto (2009:258) e Ribeiro \& Côrtes Junior (2009: 214), apresentamos, nessa subseção, os tipos de sentenças pseudoclivadas apontadas para o português brasileiro, que tomamos como direcionamento para a análise das clivadas em PA. Chamamos a atenção do leitor que, em nossa análise, substituímos o termo 'relativa livre' - que ocorre nas denominações dos autores considerados na tipologia a seguir - por 'sentença QU'. Assim o fizemos porque nossa análise desconsidera que uma sentença clivada contenha uma relativa.

\subsubsection{Pseudoclivadas Canônicas}

Segundo Braga, Kato \& Mioto (2009: 258) nas sentenças pseudoclivadas o sujeito é uma sentença $\mathrm{QU}^{30}$ e o foco é realizado pós-cópula ${ }^{31}$. Vejamos os exemplos a seguir ${ }^{32}$ :

29 Remetemos o leitor a Resenes (2009) para o estudo específico das sentenças pseudoclivadas no $\mathrm{PB}$ e os critérios que ratificam as leituras especificacionais para essas sentenças, considerando, portanto, a ausência de pronome relativo livre em suas estruturas.

30 Lembre-se: para os autores, 'relativa livre'.

31 Ribeiro \& Côrtes (2009: 214) classificam esse tipo de pseudoclivada como 'pseudoclivada básica'.

32 Braga, Kato \& Mioto (2009: 258), dado (32a-d), renumerado. 
(23) a. O que eu quero é [um cafezinho]

b. Quem telefonou foi [o João]

c. Onde a Gabriela mora é [aqui]

d. Quando a polícia vai fechar a Paulista é [amanhã]

Em (23), temos a sentença QU, em negrito, na periferia esquerda da sentença e a realização do foco de cada sentença, entre colchetes, dá-se após a cópula. Os autores chamam a atenção para o fato de que, teoricamente, qualquer pronome-Q pode encabeçar a sentença QU, conforme apontado em (23). Ribeiro \& Côrtes (2009: 215) ainda apontam para o tipo de foco que a pseudoclivada pode veicular ${ }^{33}$ :

(24) onde nós fomo foi [pra Boa Lembrança]

(25) quem foi foi [Cláudia]

Na análise de Ribeiro \& Côrtes (2009:215), a sentença em (24) apresentaria foco identificacional e em (25) apresentaria foco contrastivo.

\subsubsection{Pseudoclivadas Invertidas}

Para as pseudoclivadas invertidas, Braga, Kato \& Mioto (2009: 260) e Ribeiro \& Côrtes (2009: 215), atestam a realização do foco em posição anterior à cópula, como se vê em:

(26) [Isso] foi o que mais me impressionou ${ }^{34}$

(27) [lá] é aonde eu trabalho ${ }^{35}$

Em (26) e (27), temos o foco, entre colchetes, preposto à cópula, ou seja, em posição invertida a que apontamos para as pseudoclivadas canônicas; após a

33 Ribeiro \& Côrtes (2009: 215), dados (14c) e (15e), respectivamente, renumerados. Os autores apenas apontam o tipo de foco veiculado pela pseudoclivada, não apontando, contudo, um contexto que ratifique o caráter identificacional ou contrastivo do foco.

34 Braga, Kato \& Mioto (2009:260), dado (37), renumerado.

35 Ribeiro \& Côrtes (2009:215), dado (17b), renumerado. 
cópula temos a realização da sentença QU. Para Braga, Kato \& Mioto (2009: 260) as pseudoclivadas invertidas "são construções raras no corpus" e Ribeiro \& Côrtes (2009: 215) apontam que a pseudoclivada invertida "é de uso pouco freqüente nas comunidades em estudo $(1 \%)[\ldots] "$.

\subsubsection{Pseudoclivadas Reduzidas}

Braga, Kato \& Mioto (2009: 259) apresentam as construções pseudoclivadas reduzidas como sentenças em que ocorre uma omissão do pronome- $\mathrm{Q}^{36}$ :

(28) a. eu leio habitualmente é [o jornal]

b. ele procurava na pintura... é [a relação harmoniosa]

c. vamos encontrar ao longo do caminho... é [o sofrimento dos homens]

Em (28), as sentenças não apontam para a presença do pronome-Q que poderia encabeçar essas sentenças - (o que) eu leio habitualmente é ${ }_{0}$ jornal]. Braga, Kato \& Mioto (2009: 259) reforçam que o formato do pronome que sofreu omissão é ditado pelo constituinte que funciona como o foco da sentença ${ }^{37}$ :

(29) a. (O que) o João quer é [sambar na Portela no próximo carnaval]

b. (Onde) o João quer sambar é [na Portela] no próximo carnaval

c. (Quando) o João quer sambar na Portela é [no próximo carnaval]

\subsubsection{Pseudoclivadas Extrapostas}

Para as pseudoclivadas extrapostas, Braga, Kato \& Mioto (2009: 260) atestam um tipo de construção que contém o constituinte focalizado depois da cópula e a sentença QU depois do constituinte clivado, como se vê em ${ }^{38}$ :

(30) Foi [a Gabriela] quem as crianças viram ${ }^{39}$

\footnotetext{
36 Braga, Kato \& Mioto (2009: 259), dado (34a, b, c), renumerado.

37 Braga, Kato \& Mioto (2009: 259), dado (35a, b, c), renumerado.

38 Braga, Kato \& Mioto (2009: 259), dado (38a), renumerado.

39 Os autores apontam que embora esse exemplo seja aceito por falantes cultos, exemplos desse tipo de construção de pseudoclivada não foi atestado na amostra de língua falada que analisaram.
} 
Em (30), o foco a Gabriela é realizado logo após a cópula seguido pela sentença QU quem as crianças viram. Segundo Braga, Kato \& Mioto (2009: 260), a leitura do foco nesse tipo de pseudoclivada é sempre contrastiva.

\section{A categoria foco no português de Angola}

A partir das considerações sobre a categoria foco apresentadas na seção 3 e da tipologia sobre clivadas e pseudoclivadas apresentadas na seção 4 e 5, procedemos à descrição e análise dessa categoria no PA.

\subsection{Construções Clivadas no PA}

A seguir, apresentamos uma descrição e análise das estruturas clivadas em PA. Chamamos a atenção do leitor que, no tocante à análise realizada, consideramos os seguintes aspectos das sentenças sob enfoque:
(i) Leitura especificacional
(ii) Tipo de foco
(iii) Tipo de clivagem

\subsubsection{Clivada Canônica Pessoal e Impessoal}

Clivadas pessoais/impessoais são atestadas no corpus sob análise. A seguir apresentamos alguns exemplos.

\section{$\underline{\text { Análise I }}$}

(31) É o primeiro ano que vocês estão a enfrentar o ensino médio

Contexto: (Ba01) Foi fácil adaptar adaptar a este ambiente.

Ch00: Há uma outra coisa que é muito curiosa. $\mathbf{E}$ o primeiro ano que vocês estão a enfrentar o ensino médio e ao mesmo tempo estão a trabalhar.

Conseguem reconciliar as duas coisas?

\section{(i) Leitura especificacional}

Em (31) há a 'especificação' de um valor, o primeiro ano - o constituinte focalizado - para uma variável. Para as sentenças clivadas, essa atribuição de valor é obrigatória a fim de que se obtenha a especificidade da sentença e o 
valor atribuído seja o seu foco, conforme se vê na representação de sua AS na tipologia a seguir.

\section{(ii) Tipo de foco}

Em (31), temos 'foco de informação' representado pelo constituinte o primeiro ano. Abaixo, apresentamos a AS de (1):

$A_{1}$ : Existe um $x$ tal que vocês (os alunos) estão a enfrentar $x$.

$A_{2}: O x$ tal que vocês (os alunos) enfrentam $x={ }_{F}$ o primeiro ano $]$.

A A 1 representa o contexto assertivo ou a pressuposição da sentença; a $\mathrm{A}_{2}$ recebe a denominação de asserção principal, sendo uma sentença equativa que possui como predicado o elemento focalizado.

\section{(iii) Tipo de clivada}

Em (31), temos uma clivada canônica do tipo 'pessoal' por apresentar concordância entre o tempo verbal da cópula (ê) e o constituinte clivado (o primeiro ano), assim como o tempo verbal da oração encaixada (estão) - tempo presente.

\section{Análise II}

(32) A Teté é a primeira vez que veio para cá.

Contexto: Ch00: Vai passar de classe?

Te12: Sim, vou.

Ch00: Uma pergunta um pouco curiosa, a Teté é a primeira vez que veio para cá.

Como é, conseguiu adaptar-se facilmente à vida de internato ou tá difícil?

Te12: Não, consegui adaptar facilmente.

\section{(i) Leitura especificacional}

Em (32), há a 'especificação' de um valor, a primeira vez - o constituinte focalizado - para uma variável, conforme se vê abaixo na representação de sua AS. 


\section{(ii) Tipo de foco}

Em (32), temos foco de informação representado pelo constituinte a primeira vez. A seguir, temos a representação de sua AS:

$\mathrm{A}_{1}$ : Existe um $\mathrm{x}$ tal que Teté veio $\mathrm{x}$

$$
\left.\mathrm{A}_{2}: \mathrm{O} x \text { tal que Teté veio } \mathrm{x}={ }_{\mathrm{F}} \text { a primeira vez }\right]
$$

\section{(iii) Tipo de clivada}

Em (32), temos uma clivada canônica do tipo 'impessoal' por não apresentar concordância entre o tempo verbal da cópula (è) e o tempo verbal da oração encaixada (veio) - tempo passado.

\section{Análise III}

(33) Não, é o segundo ano que vivo no internato.

Contexto: Ch00: Já vive há muito tempo no internato ou apenas é o primeiro ano? Di21: Não, é o segundo ano que vivo no internato.

\section{(i) Leitura especificacional}

A leitura especificacional em (33) aponta para a determinação de um valor - é o segundo ano - ao constituinte focalizado disparando as leituras de contrastividade, exaustividade e exclusividade.

\section{(ii) Tipo de foco}

Em (33), temos foco contrastivo representado pelo constituinte o segundo ano. Abaixo, temos a representação de sua AS:

$A_{1}$ : Há um x que (Dinho) vive no internato

$\mathrm{A}_{2}$ : Não é o caso que o x (o qual (Dinho) vive no internato) $=$ terceiro ano \&

O x o qual (Dinho) vive no internato $=$ segundo ano

\section{(iii) Tipo de clivada}

Em (33), temos uma clivada canônica do tipo 'pessoal' por apresentar concordância entre a pessoa do tempo verbal da cópula (ê) e o constituinte clivado 
(o segundo ano), e ainda a concordância do tempo verbal da cópula e o tempo verbal da oração encaixada (vivo) - tempo presente.

\subsubsection{Clivada Invertida}

Nas clivadas invertidas, o foco é invertido para antes da cópula, que tende a permanecer invariante e o foco tem sempre uma leitura contrastiva. Esse tipo de clivada é atestado no corpus sob análise como se vê nos exemplos a seguir.

\section{Análise I}

(34) por motivo de determinadas ordens é que fui desviado para administração pública.

Contexto: Ch00: O Chibi escolheu esse curso voluntariamente ou foi encaminhado?

Ch14: Bom, eu não escolhi o curso voluntariamente porque na época em que começou as inscrições eu não encontrava-me cá, encontrava em Benguela, quem veio fazer a inscrição foi o meu pai. Ele escolheu pa finanças mas não havia finança então outra alternativa seria contabilidade e gestão mas não sei por motivo de determinadas ordens é que fui desviado para administração pública.

\section{(i) Leitura especificacional}

Em (34), a leitura especificacional é destacada pelas leituras de contrastividade, exaustividade e exclusividade que se evidencia pela tomada de um valor - contrastivo - a uma variável, e pela ordem do constituinte focalizado, conforme apontamos a seguir.

\section{(ii) Tipo de foco}

Em (34), temos foco contrastivo representado pelo constituinte por motivo de determinadas ordens. Abaixo, temos a representação de sua AS:

$\mathrm{A}_{1}$ : Há um x que Chibi foi desviado para administração publica $\mathrm{A}_{2}$ : Não é o caso que o x (o qual Chibi foi desviado para administração pública $)=$ voluntariamente

$\&$ 
O x o qual Chibi foi desviado para administração pública $\mathrm{x}=$ por motivo de determinadas ordens

\section{(iii) Tipo de clivada}

Em (34), temos uma clivada do tipo invertida por apresentar o foco (por motivo de determinadas ordens) em posição anterior a cópula (ê). A cópula apresentou-se invariante em relação ao tempo verbal da oração encaixada (fui) e o foco, nesse caso, também se confirmou como do tipo contrastivo.

\section{Análise II}

(35) só os miúdos é que têm que respeitar

Contexto: Tc19: É fácil sim desde que haja respeito mútuo, sim.

Ch00: $\mathrm{E}$ agora que os mais velhos põem na cabeça que só os miúdos é que têm de respeitar.

Tc19: Nesse caso há que entender-se porque quando os velhos pensam assim, temos que arranjar maneira de nos entendermos, depois...

\section{(i) Leitura especificacional}

Em (35), a leitura especificacional é realçada pela atribuição das leituras de contrastividade, exaustividade e exclusividade para o constituinte focalizado os miúdos acompanhado do advérbio só que reforça, na sentença, as principais propriedades de uma sentença especificacional.

\section{(ii) Tipo de foco}

Em (35), o constituinte clivado os miúdos veicula foco do tipo contrastivo conforme apontado em sua AS abaixo:

$A_{1}$ : Há um x que os velhos põem na cabeça que somente $x$ tem de respeitar

$A_{2}$ : Não é o caso que o x (o qual os velhos põem na cabeça que somente $\mathrm{x}$ tem de respeitar $)=$ adolescentes

\&

O x o qual os velhos põem na cabeça que somente x tem de respeitar $=$ os miúdos 


\section{(iii) Tipo de clivada}

Em (35), temos uma clivada do tipo invertida por apresentar o foco (os miúdos) em posição anterior a cópula (ê) que se manteve invariável e o foco mostrou-se contrastivo.

\subsubsection{Interrogativa Clivada}

As interrogativas clivadas atestam uma estrutura com a cópula e o complementizador que seguindo um sintagma-QU, conforme se vê nos exemplos abaixo.

\section{Análise I}

(36) O que é que tens a dizer sobre o fim do ano lectivo?

Contexto: Ch00: Tá a conseguir superar as médias. Arménio, o que é que tens a dizer sobre o fim do ano lectivo?

Ar04: Bem. Para mim o fim do ano lectivo está a ir com bastante dificuldade.

\section{(i) Leitura especificacional}

Em (36), temos uma sentença do tipo interrogativa em que é atribuído um valor ao pronome-QU o que, resultando no foco sentencial na periferia esquerda da sentença. O pronome interrogativo em (36) apresenta as leituras de contrastividade, exaustividade e exclusividade, explicitadas na resposta de Ar04 pelo sintagma preposicional com bastante dificuldade.

\section{(ii) Tipo de foco}

A literatura sobre a tipologia de foco não contempla o constituinte focalizado, ou pronome QU, nas sentenças interrogativas clivadas. No entanto, consideramos que esse constituinte pode ser inserido em uma tipologia para o foco, tanto por veicular uma leitura especificacional como por apresentar uma entonação - uma das particularidades do foco - para esse tipo de clivada, por exemplo, no português. A seguir, apresentamos a AS de (36):

$\mathrm{A}_{1}$ : Existe um $\mathrm{x}$ tal que Arménio dirá $\mathrm{x}$ $\mathrm{A}_{2}: \mathrm{O} x$ tal que Arménio dirá $\mathrm{x}=\left[_{\mathrm{F}} \mathrm{o}\right.$ que $]$ 
Chamamos a atenção do leitor para o fato da possibilidade do pronome-QU o que em (36), ser substituído por outro pronome-QU como quando: Quando é que tens a dizer algo sobre ofim do ano lectivo? A substituição do pronome-QU na sentença interrogativa clivada define, portanto, qual o valor assumido pelo foco sentencial na resposta a essa pergunta. Em (36, o pronome-QU exige como resposta uma situação ou algo que defina a opinião do falante sobre o final do ano lectivo. A substituição do pronome o que por quando, no entanto, exige que a informação a ser veiculada seja do tipo temporal.

\section{(iii) Tipo de clivada}

Em (36), temos uma clivada interrogativa por apresentar um sintagma-QU na periferia esquerda da sentença e em seguida a cópula (ẻ) e a partícula focalizadora que. O pronome-QU interrogativo o que é gerado na posição de argumento interno do verbo dizerer. Em uma segunda etapa, é 'ensanduichado' invertidamente em uma estrutura de clivagem.

\subsection{Perguntas QU Fronteadas Seguidas de QUE sem Cópula}

Para as sentenças comumente classificadas como 'interrogativas clivadas sem cópula' no PB/português afro-brasileiro, corroboramos, para o PA, a proposta de Oliveira (no prelo) de considerá-las como tipo de sentenças em que não ocorre o processo de clivagem - ver (4.1.7/4.1.7.1).

Atestamos a ocorrência desse tipo sentencial no PA nos parecendo ser um caso bem produtivo na língua como o é no $\mathrm{PB} /$ português afro-brasileiro ${ }^{40}$. Observe exemplos a seguir:

(37) Já tem algum plano onde que vai trabalhar?

(38) Onde que vai seguir a faculdade?

(39) Quando que pensa trabalhar?

40 Em documentário produzido por uma TV portuguesa, por exemplo, vimos depoimentos que estavam sendo tomados de falantes 'cultos' angolanos. Foi interessante ouvi-los pronunciarem claramente expressões com o fenômeno em questão: perguntas QU fronteadas seguidas de que sem cópula como: "o que que vocês fizeram com as armas?" O interessante é que a 'legenda' portuguesa (PE) 'traduzia' todas essas construções como interrogativas clivadas (com cópula) - “o que é que vocês fizeram com as armas?”. 
(40) A propósito, donde que a Teté veio encaminhada?

(41) Onde que tem conseguido esses livros?

(42) Onde que está mais evoluído?

Os exemplos (37) a (42) em PA apresentados acima, se classificados dentro da tipologia tradicional que apresentamos em (4.1.7.), seriam analisados como sentenças 'interrogativas clivadas sem cópula’ - um caso de estrutura biclausal. Ratificamos, no entanto, nossa posição de classificar sentenças como essas como monoclausais. Logo, a nosso ver, os pronomes QUs em (37)-(42) estaria em uma posição de foco - [Spec, Foc] - (posição de especificador do sintagma foco), seguido de um marcador de foco - o elemento 'que'.

\subsection{Construções Pseudoclivadas no PA}

A seguir, apresentamos uma descrição e análise das estruturas pseudoclivadas em PA. Chamamos a atenção do leitor que, no tocante à análise realizada, consideramos os seguintes aspectos das sentenças sob enfoque:

\section{(i) Leitura especificacional \\ (ii) Tipo de foco \\ (iii) Tipo de clivagem}

\subsubsection{Pseudoclivada Canônica}

Para as sentenças pseudoclivadas atestamos que o sujeito é uma sentença QU e o foco é realizado pós-cópula.

\section{Análise I}

(43) Quem veio fazer a inscrição foi o meu pai

Contexto: Ch00: O Chibi escolheu esse curso voluntariamente ou foi encaminhado?

Ch14: Bom, eu não escolhi o curso voluntariamente porque na época em que começou as inscrições eu não encontrava-me cá, encontrava em Benguela, quem veio fazer a inscrição foi meu pai. 


\section{(i) Leitura especificacional}

Em (43), uma sentença pseudoclivada canônica, temos a leitura especificacional atribuída pelo valor atribuído ao constituinte meu pai como foco sentencial. O foco sentencial meu pai aponta para as leituras específicas das sentenças que sofrem o processo de clivagem: as leituras de contrastividade, exclusividade e exaustividade.

\section{(ii) Tipo de foco}

Pelo contexto em que a sentença foi proferida, notamos que a informação veiculada não era pressuposta pelo interlocutor e meu pai preenche o valor sentencial para se tornar o foco de informação.

$A_{1}$ : Existe um $x$ tal que $x$ foi fazer a inscrição

$\mathrm{A}_{2}$ : $\mathrm{O} \times \mathrm{x}$ tal que foi fazer a inscrição $\mathrm{x}={ }_{\mathrm{F}}$ meu pai $]$

\section{(iii) Tipo de clivagem}

A sentença em (43) apresenta a formação canônica de uma pseudoclivada em que podemos observar a sentença QU ocupando a posição de sujeito da sentença e o constituinte com traço de foco está situado em posição após a cópula.

Análise II

(44) O que penso fazer é o criar

Contexto: Jo127: E a senhora não desconfiou com nenhuma aí na sua rua? Du126: Não, não, já vivo lá há muitos anos e conheço todas que tem bebê.

Jo127:E o que que a criança tem assim com essa pele?

Du126: Não sei mais ou menos que ainda a levei ao médico.

Jo127: E o que que a senhora pensa fazer?

Du127: O que penso fazer é o criar ou então a família vir procurar.

\section{(i) Leitura especificacional}

Em (44), há a especificação de um valor, o criar - foco sentencial da sentença - a uma variável, apontando para leituras específicas de sentenças clivadas, como a 
contrastividade, exclusividade e exaustividade, reforçadas pela posição em que o foco se encontra na sentença - posição invertida - conforme apontamos abaixo.

\section{(ii) Tipo de foco}

O foco veiculado em (44) é do tipo informacional. Abaixo, temos a representação de sua AS:

$A_{1}$ : Existe um $x$ tal que a senhora pensa $x$

$\mathrm{A}_{2}: \mathrm{O} x$ tal que a senhora pensa $\mathrm{x}={ }_{\mathrm{F}} \mathrm{O}$ criar $]$

\section{(iii) Tipo de clivagem}

Em (44), estamos diante de uma pseudoclivada canônica. A sentença QU encabeça a periferia esquerda da sentença e o constituinte com traço de foco está em posição pós-cópula.

\subsubsection{Pseudoclivadas Invertidas}

Para as pseudoclivadas invertidas, atestamos uma realização do foco em posição anterior à cópula. $\mathrm{O}$ foco, nesse caso, é contrastivo.

\section{Análise I}

(45) Cassettes é o que havia de mais

\section{Contexto: E: Praticou?}

Na25: Um pouco. Depois veio o Michael Jackson, a moda, e havia dancings. A malta própria, pronto desenrascávamos. Pedíamos autorização por exemplo um prédio, terraço, e montávamos lâmpadas assim coloridas, pessoas que vinham pintávamos, enfeitávamos aquilo e prontos. De noite, vinha sempre alguém com um aparelho, dava um som normal. Cassettes é o que havia de mais. Cada um desenrasgava isso.

\section{(i) Leitura especificacional}

Em (45), o constituinte cassetes na periferia esquerda da sentença é o responsável pela leitura especificacional que se tem na sentença ao veicular o foco sentencial e explicitar as leituras de contrastividade, exaustividade e exclusivi- 
dade, reforçadas pela ordem inversa do constituinte na sentença e o tipo de foco que aponta, conforme veremos a seguir.

\section{(ii) Tipo de foco}

O foco em (45), representando pelo constituinte cassetes é do tipo contrastivo. Apresentamos, abaixo, a AS dessa sentença:

$\mathrm{A}_{1}$ : Há um $\mathrm{x}$ que havia $\mathrm{x}$ de mais

$\mathrm{A}_{2}$ : Não é o caso que o $\mathrm{x}$ (o qual $\mathrm{x}$ havia de mais $)=$ discos

$\&$

$\mathrm{O}$ x o qual $\mathrm{x}$ havia de mais $=$ cassetes

\section{(iii) Tipo de clivagem}

Em (45), temos uma pseudoclivada invertida. O foco cassetes é realizado em posição anterior a cópula e sua posição invertida na sentença ressalta o caráter contrastivo que ele veicula.

\section{Conclusão}

Iniciamos nosso trabalho com uma breve apresentação de alguns aspectos linguísticos de Angola, seguida de uma seção em que identificamos a natureza de nosso corpus. Embora o corpus tenha sido constituído de interações orais, ele se apresentou na forma escrita e essa condição delimitou nossa abordagem de apreensão da categoria foco tratada em nosso trabalho - não pudemos analisar aspectos da entonação. Logo, a razão principal de termos nos detido na análise da clivagem, foi porque podíamos analisar o foco prescindindo da análise de aspectos prosódicos.

Apresentamos a definição da categoria foco que tomamos nesse trabalho, ressaltando a estrutura de asserção (AS) e a tipologia de foco. No tocante às construções clivadas e pseudoclivadas, assumimos a abordagem de que essas estruturas não contêm uma relativa e que

têm uma leitura especificacional. Outro fator importante para nossa análise foi pontuar que, com relação ao fenômeno construções Qu fronteadas seguidas de que sem cópula nossa abordagem seguiria proposta de análise monoclausal. Logo, essas construções atestadas em PA foram por nós analisadas não como construções clivadas, mas sim como uma construção monoclausal com marcação específica de foco. 
A tipologia para as sentenças clivadas e pseudoclivadas descrita na literatura foi a base para que delimitássemos os tipos de construções com clivagem no PA. Apresentamos, portanto, para essa língua, uma tipologia baseada em estudos sobre a clivagem no PB/português afro-brasileiro e PE.

Em nossa análise da clivagem no PA verificamos os seguintes tipos de clivadas: (i) clivada canônica pessoal e impessoal, (ii) clivada invertida, (iii) interrogativa clivada. Verificamos ainda os seguintes tipos de pseudoclivadas: (i) pseudoclivada canônica, (ii) pseudoclivada invertida.

A partir da tipologia de foco apresentada verificamos que os tipos de foco presentes no PA, atestados em nosso corpus, foram do tipo 'informacional' e 'contrastivo.'

Chamamos a atenção do leitor, também, para o fato de em nosso corpus em análise, não encontrarmos uma ocorrência, em grande número, de sentenças pseudoclivadas. Esse fato, embora preliminar e que carece de estudos mais aprofundados, aponta para uma aproximação do PA com o PB na predileção para a realização de sentenças clivadas na periferia esquerda da sentença. O PE, por outro lado, apresenta uma predileção por sentenças pseudoclivadas. Remetemos o leitor ao trabalho de Fernandes (2007) que aponta para esse tipo de uso ente clivadas e pseudoclivadas entre o PB e o PE.

Destacamos ainda o fato de que o PA atesta a presença de sentenças classificadas tradicionalmente como 'interrogativas clivadas sem cópula' - que tratamos nesse trabalho como perguntas-QU fronteadas seguidas de 'que' sem cópula. Nossa abordagem, como já dito, afasta-se da maioria das análises tomadas para o português - que analisam tais construções como clivadas com apagamento da cópula. Aproximamo-nos, de propostas de análises, no tocante a essas construções, que relacionam esse tipo de marcação de foco à marcação de foco de línguas do oeste da África e ainda a língua crioulas.

Ao término de nossas considerações, ratificamos a necessidade de que estudos sobre o foco (e o tópico) em PA tenham continuidade. Ressaltamos ainda a importância de estudos comparativos sobre o português falado na África - como o PA - e o PB. Observamos, por exemplo, as similaridades entre o PB e o PA no tocante ao fenômeno perguntas-QU fronteadas seguidas de 'que' sem cópula, que este trabalho apenas tangenciou, e percebemos o quanto esta temática é intrigante. 


\section{Referências bibliográficas}

ADESANYA, M. (2007). Problems encountered by Yoruba speakers in learning English cleft constructions. In: Journal of the Linguistic Association of Nigeria 10. p. 147-155.

BRAGA, M. L.; KATO, M. A.; MIOTO, C. (2009). As construções-Q no português brasileiro falado. In: Gramática do português culto falado no Brasil - A construção da sentença. M. A. Kato, M. do Nascimento (orgs.). Campinas: Editora da Unicamp, p.241-289.

CHAVAGNE, J-P. (2005). La langue portugaise d'Angola - etude dês écrits par rapport à la norma europénne du portugais. Thèse de doctorat - Université Lumiér. Lyon 2, Faculte de Langues, Paris. Umpublished.

CHENG, L. L. S. (1991). On the typology of wh-questions. PhD Dissertation, University of Massachusetts, Amherst.

FERNANDES, F.R. (2007). Ordem, focalização e preenchimento em português: sintaxe e prosódia. Tese de Doutorado. Instituto de Estudos da Linguagem, UNICAMP.

GREEN, M. (2007). Focus in Hausa. Publications of the Philological Society, 40.Oxford: Blackwell.

GROLLA, E. (2005). Sobre a aquisição tardia de QU-in situ em português brasileiro. D.E.L.T.A., 21:1, p.57-63.

HEINE, B; NURSE, D. (2000). Introduction. In: B. Heine, D. Nurse (eds). African Languages: An introduction, p. 1-10.

HOLM, J. (1989). Pidgins and creoles, vol. 2. Cambridge: Cambridge University Press.

KATO, M. A. \& MIOTO, C. (2005). A multi-evidence study of European and Brazilian Wh-question. In: H. S. Kepser, M. Reis. (eds). Linguistic evidence: theoretical, quantitative and computational perspectives. Hague: Mouton, p. 307-328.

KATO, M. A. \& RAPOSO, E. (1996). European and Brazilian Portuguese word order: questions, focus and topic constructions. In: C. Quicoli, M. Saltareli, M. L. Zubizarreta (eds.) Aspects of romance linguistics. Selected papers from the LSRL XXVI. Washington: Georgetown University Press, p. 267-278.

KISS, K. (1998) Identificacional focus versus information focus. Language:74 (2), p. 245-273.

KUNO, S. (1972). Functional sentence perspective: a case study from Japanese and English. Linguistic Inquiry, vol. 3, p. 269-320.

MODESTO, M. (2001). As construçẽes clivadas no português do Brasil: relaçōes entre interpretação focal, movimento sintático e prosódia. São Paulo: Humanitas - FFLCH/USP.

MIOTO, C. \& E. V. NEGRÃO. (2007). As sentenças clivadas não contêm uma relativa. In: A. T. Castilho, M. A. Torres-Morais, R. E. V. Lopes, S. M. Cyrino (orgs.). Descrição, bistória e aquisição do português brasileiro. Campinas, SP: Pontes/FAPESP, p. 159-184 
OLIVEIRA, M. S. D. de. (No prelo). Focus in Brazilian Portuguese. In: M. M. T. Petter, M. Vanhove (orgs.). Études afro-brésiliennes. Paris : Éditions Karthala.

OLIVEIRA, M. S. D., HOLM, J. (2011). Estruturas-QU fronteadas e o 'foco gramaticalmente controlado' - a participação de línguas africanas em línguas parcialmente e completamente reestruturadas. Revista PAPIA, 21, p. 23-38.

PETTER, M.M.T. (2008). Aspectos morfossintáticos comuns ao português angolano, brasileiro e moçambicano. Tese de livre docência. Universidade de São Paulo.

RESENES, M. S. de. (2009). Sentenças pseudo-clivadas no português brasileiro. Dissertação de Mestrado. Florianopólis: UFSC.

RIBEIRO, I. \& CÔRTES JÚNIOR, M. (2009). As construções pseudoclivadas e clivadas. In: D. Lucchesi., A. Baxter.; I. Ribeiro. (orgs.). O português afro-brasileiro. Salvador: EDUFBA, p. 209-230.

SANTOS, E. F. (2010). A periferia esquerda no português de Angola. Dissertação de Mestrado. Universidade de São Paulo.

WATTERS, J. (1979). Focus in Aghem. In: Hyman, L. (ed.). Aghem grammatical structures. Los Angeles: University of Southern California, Southern California Occasional Papers in Linguistics No. 7, p.137-97.

ZAU, F. (2009). O estatuto das linguas de origem Africana. Jornal de Angola. Disponível em: http://jornaldeangola.sapo.ao/19/46/o_estatuto_das_linguas_de_origem_africana. Acesso em 31/05/2010.

ZUBIZARRETA, M. L. (1997). Prosody, focus and word order. University of Southern Califórnia, Departamento of Linguistics, Los Angeles, CA, Manuscript.

Recebido em: 20/12/2010

Aprovado em: 01/05/2011 